\title{
LXXXVIII. The motion of electrons in carbon dioxide
}

\section{M.F. Skinker}

To cite this article: M.F. Skinker (1922) LXXXVIII. The motion of electrons in carbon dioxide, Philosophical Magazine Series 6, 44:263, 994-999, DOI: 10.1080/14786441208562575

To link to this article: http://dx.doi.org/10.1080/14786441208562575

曲 Published online: 08 Apr 2009.

Submit your article to this journal $\pi$

Q View related articles $₫$

4 Citing articles: 18 View citing articles 


\section{[ 994 ]}

LXXXVIII. The Motion of Electrons in Carbon Dioxide. By M. F. Skinker, Rhodes Scholar, Exeter College, Oxford *.

TN some recent publications of the Philosophical Magazine, 1 Prof. J. S. Townsend and Mr. V. A. Bailey $\dagger$ describe their experiments on the motion of electrons in liydrogen, nitrogen, oxygen, and argon.

In this paper I wish to give the results of similar experiments with carbon dioxide and to compare the results.

The apparatus used had the same dimensions and was similar to the one described in the above papers. The electrode $\mathrm{E}_{2}$, in fig. $1 \neq$, however, was not exactly under the slit in $\mathrm{B}$, but was 0.6 millimetre to the right. In order to find the velocity of agitation $u$ it is necessary to find the normal distribution-curve when the centre of the stream is 0.6 millimetre from the centre of the electrode $\mathrm{E}_{2}$. In this case $R$, the ratio of the current received by the central electrode to the total current, is given by the curve in fig. 2 , $Z$ being the electric force in volts per centimetre.

Fig. 2.

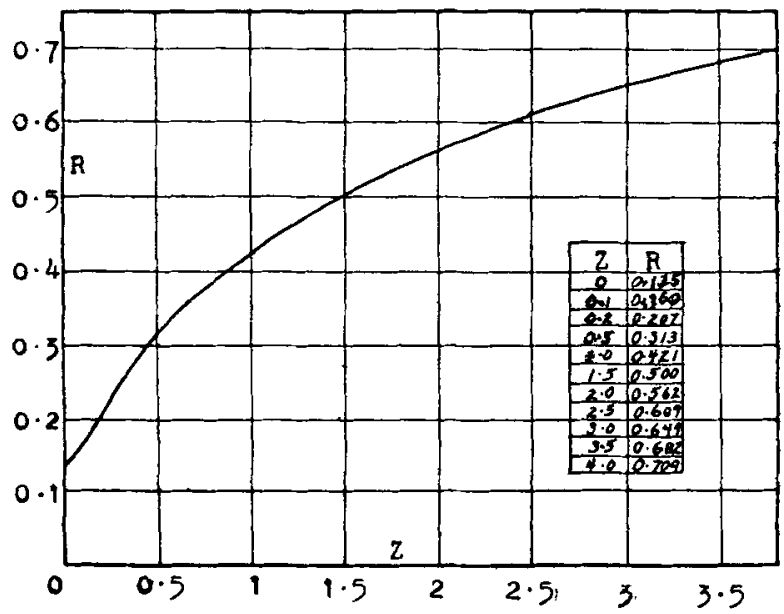

The curve differs slightly from the curve which corresponds to the case in which the centre of the stream coincides with the centre of the electrode $\mathrm{E}_{2}$.

* Communicated by Prof. J. S. Townsend, F.R.S.

+ Phil. Mag. vol. xlii. Dec. 1921, and vol. xliii. March 1922.

† Fig. 1, vol. xlii. p. 875 . 
The calculation of this curve will be explained in a future paper by Prof. J. S. Townsend and Mr. V. A. Bailey.

In order to find the velocity of the electrons in the direction of the electric force, two different magnetic forces may be used. With this eccentricity of 0.6 millimetre the stream may be deflected 1.9 millimetres to the left or 3.1 millimetres to the right. In these experiments all deflexions were to the right, as the determinations with the larger deflexions are the more accurate.

The results of the experiment are given in Table I., where $p$ is the pressure in millimetres of mercury, $k$ the factor by which the kinetic energy of the electron exceeds the kinetic energy of a molecule of a gas at $15^{\circ} \mathrm{C}$.,

W the velocity of the electrons in the direction of the electric force in centimetres per second.

TABLE I.

\begin{tabular}{|c|c|c|c|c|}
\hline$p$ & $\mathrm{Z}$. & $\mathbf{Z} / p$ & $k$. & $W \times 10^{-5}$ \\
\hline $\begin{array}{r}20 \cdot 23 \\
9.82 .\end{array}$ & $\begin{array}{l}4 \cdot 16 \\
2 \cdot 08\end{array}$ & $\begin{array}{l}0.206 \\
0.222\end{array}$ & $\begin{array}{l}1 \cdot 19 \\
1 \cdot 283\end{array}$ & $1 \cdot \overline{18}$ \\
\hline $\begin{array}{l}9 \cdot 82 \\
5 \cdot 06\end{array}$ & $\begin{array}{l}4 \cdot 16 \\
2 \cdot 08\end{array}$ & $\begin{array}{c}0.444 \\
0.411\end{array}$ & $\begin{array}{l}1 \cdot 29 \\
1 \cdot 277\end{array}$ & $\begin{array}{l}2 \cdot 41 \\
2 \cdot 45\end{array}$ \\
\hline $\begin{array}{l}9 \cdot 82 \\
5 \cdot 061 \\
2 \cdot 49\end{array}$ & $\begin{array}{l}8 \cdot 33 \\
4 \cdot 16 \\
2 \cdot 08\end{array}$ & $\begin{array}{l}0.888 \\
0.822 \\
0.835\end{array}$ & $\begin{array}{l}\overline{1} \cdot 36 \\
1 \cdot 36\end{array}$ & $\begin{array}{l}4 \cdot 91 \\
4 \cdot 55 \\
4 \cdot 67\end{array}$ \\
\hline $\begin{array}{l}5 \cdot 06 \\
2 \cdot 49 \\
1 \cdot 26\end{array}$ & $\begin{array}{l}8 \cdot 33 \\
4 \cdot 16 \\
2 \cdot 08\end{array}$ & $\begin{array}{l}1.647 \\
1.67 \\
1.66\end{array}$ & $\begin{array}{l}1 \cdot 72 \\
1 \cdot 64\end{array}$ & $\begin{array}{l}9 \cdot 42 \\
9 \cdot 81 \\
9 \cdot 47\end{array}$ \\
\hline $\begin{array}{r}5 \cdot 06 \\
2 \cdot 49 \\
1 \cdot 26 \\
\cdot 62\end{array}$ & $\begin{array}{r}16 \cdot 67 \\
8 \cdot 33 \\
4 \cdot 16 \\
2 \cdot 08\end{array}$ & $\begin{array}{l}3 \cdot 30 \\
3 \cdot: 2 \\
3 \cdot 29 \\
3 \cdot 32\end{array}$ & $\begin{array}{l}-\overline{-} \\
2 \cdot 88 \\
2 \cdot 79 \\
2 \cdot 89\end{array}$ & $\begin{array}{l}22 \cdot 4 \\
23 \cdot 8 \\
23 \cdot 6 \\
24 \cdot 5\end{array}$ \\
\hline $\begin{array}{r}2.49 \\
1.26 \\
.63\end{array}$ & $\begin{array}{r}16 \cdot 67 \\
8 \cdot 33 \\
4 \cdot 16\end{array}$ & $\begin{array}{l}6 \cdot 64 \\
6 \cdot 59 \\
6 \cdot 64\end{array}$ & $\begin{array}{l}22 \cdot 1 \\
21 \cdot 1 \\
23 \cdot 1\end{array}$ & $\begin{array}{l}82 \cdot 4 \\
82 \cdot 4 \\
81 \cdot 4\end{array}$ \\
\hline $\begin{array}{l}2 \cdot 49 \\
1 \cdot 26\end{array}$ & $\begin{array}{l}33 \cdot 33 \\
16 \cdot 67\end{array}$ & $\begin{array}{l}13 \cdot 4 \\
13.2\end{array}$ & $\begin{array}{r}60 \cdot 6 \\
60 \cdot 1\end{array}$ & $\begin{array}{l}118 \\
124\end{array}$ \\
\hline $\begin{array}{r}1.26 \\
.63\end{array}$ & $\begin{array}{l}33 \cdot 33 \\
16 \cdot 67\end{array}$ & $\begin{array}{l}26 \cdot 4 \\
26 \cdot 6\end{array}$ & $\begin{array}{l}81 \cdot 3 \\
91\end{array}$ & $\begin{array}{l}142 \\
150\end{array}$ \\
\hline$\cdot 63$ & $33: 33$ & $53 \cdot 2$ & 147 & 202 \\
\hline
\end{tabular}


996

\author{
Mr. M. F. Skinker on the
}

The values of $\mathrm{W}$ and $k$ are plotted against $\frac{Z}{p}$ in figs. 3-6, together with the curves for hydrogen and nitrogen.

Fig. 3.

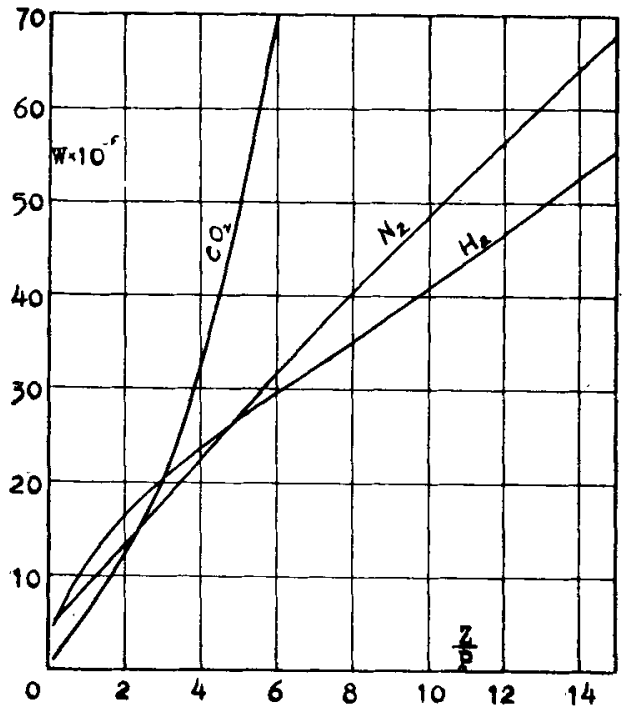

Fig. 4.

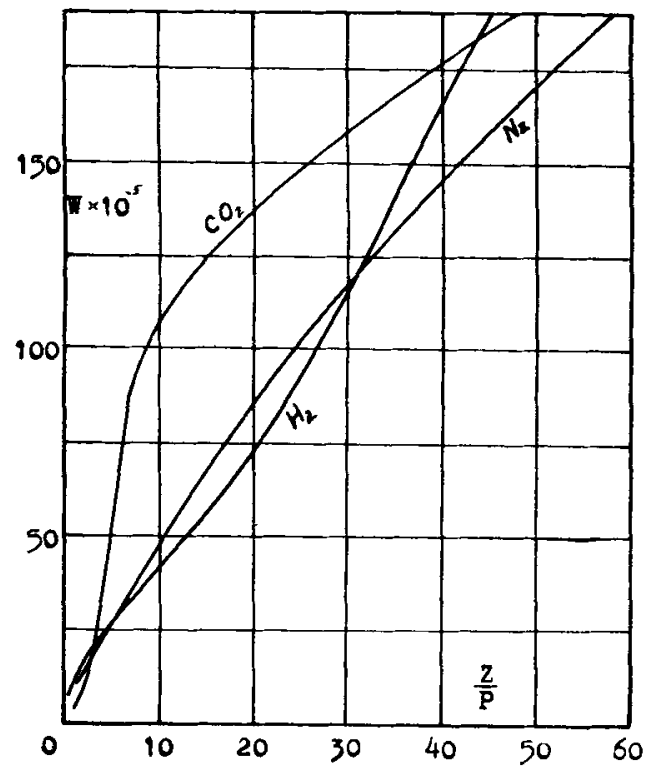


Motion of Electrons in Carbon Dioaide.

Fig. 5.

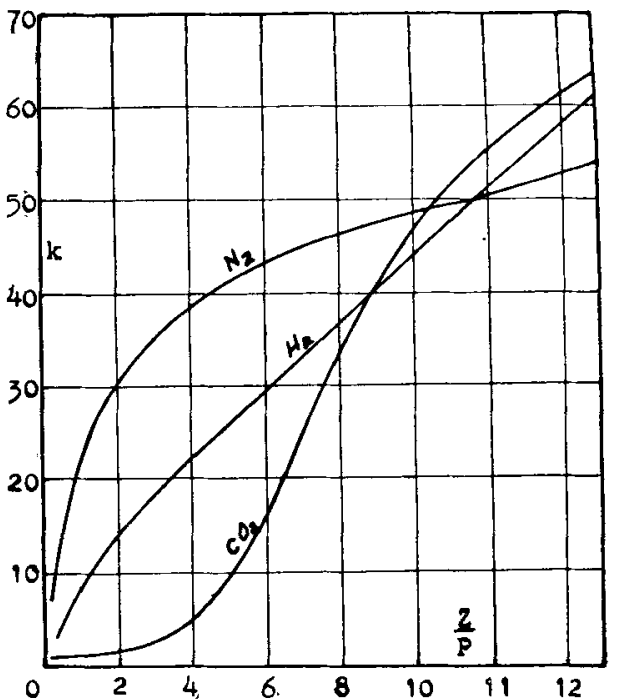

Fig. 6.

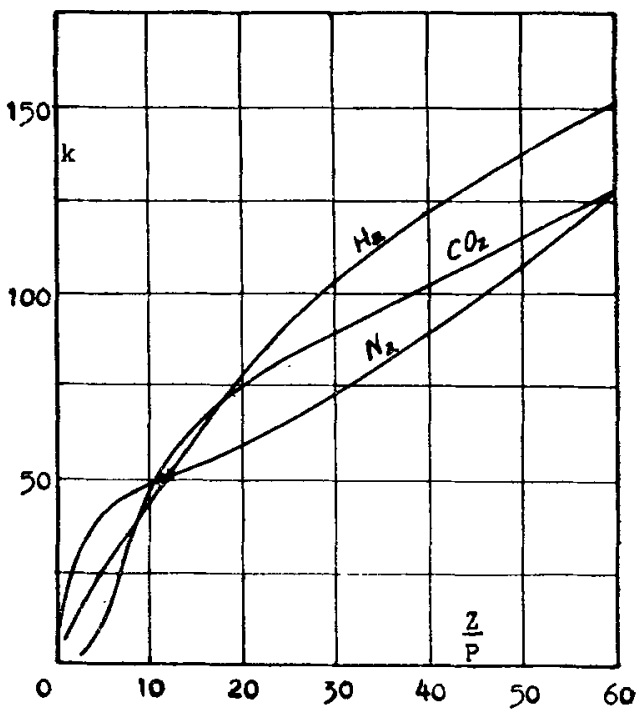


In the following table, $u$ is the velocity of agitation of electrons in centimetres per second, $l$ the mean free path of the electron in centimetres, $p$ the pressure of the gas in millimetres of mercury, and $\lambda$ the proportion of energy of the electron lost in collision with a molecule.

The formulæ connecting $u, l$, and $\lambda$ with the quantities $k$ and $W$ being :-

$$
\begin{aligned}
u & =1.15 \times 10^{\prime} \times \sqrt{k}, \\
\mathrm{~W} & =\frac{\mathrm{Z}}{p} \times \frac{e}{m} \times \frac{l p}{u} \times 0.815, \\
\lambda & =2.46 \times \frac{\mathrm{W}^{2}}{u^{2}} .
\end{aligned}
$$

\begin{tabular}{|c|c|c|c|c|c|}
\hline $\mathrm{Z} / p$. & $k$. & $\mathrm{W} \times 10^{-6}$ & $u \times 10^{-6}$ & $l p \times 100$ & $\lambda \times 10^{4}$ \\
\hline 50 & 139 & $19 \cdot 5$ & $135 \cdot 7$ & $3 \cdot 67$ & 506 \\
\hline 40 & $117 \cdot 5$ & $17 \cdot 75$ & $124: 8$ & $3 \cdot 84$ & 497 \\
\hline 30 & 96 & $15 \cdot 9$ & $112 \cdot 8$ & $4 \cdot 15$ & 487 \\
\hline 20 & 75 & $13 \cdot 8$ & $99+5$ & $4 \cdot 76$ & 472 \\
\hline 10 & 47 & $10 \cdot 8$ & $78 \cdot 9$ & 5.91 & 460 \\
\hline $6 \cdot 5$ & $20 \cdot 7$ & $7 \cdot 8$ & $52 \cdot 4$ & $4 \cdot 36$ & 543 \\
\hline 50 & 9 & $5 \cdot 0$ & $34 \cdot 5$ & $2 \cdot 39$ & 516 \\
\hline 4 & $4: 8$ & 32 & $25 \cdot 2$ & 1.40 & 397 \\
\hline 3 & $2 \cdot 3$ & $2 \cdot 0$ & $17 \cdot 5$ & $\cdot 809$ & 321 \\
\hline 2 & $1 \cdot 8$ & $1 \cdot 18$ & $15 \cdot 4$ & .630 & 144 \\
\hline 1 & 1.5 & $\cdot 55$ & $14 \cdot 1$ & 538 & $37 \cdot 4$ \\
\hline 0.5 & $1 \cdot 3$ & $\cdot 25$ & $13 \cdot 1$ & $\cdot 454$ & $8 \cdot 95$ \\
\hline 0.25 & $1 \cdot 2$ & $\cdot 12$ & $12 \cdot 6$ & $\cdot 419$ & $2 \cdot 34$ \\
\hline
\end{tabular}

TABLE II.

In order to determine whether or not there were any ions in the stream, the magnetic force was increased, to see if the stream were completely deflected off $\mathrm{E}_{1}$ and $\mathrm{E}_{2}{ }^{*}$. This was found to be possible when using a magnetic force which was comparatively small and which would not have been sufficient to deflect ions from the plates. Also the quantity $k$ and the velocity $W$ were found to remain constant with different values of $Z$ and $p$ when $\frac{Z}{p}$ was constant; these results show that there could not have been any permanent ions formed in the gas.

* Fig. 1, vol. xlii. p. 875 . 
With values of $\frac{\mathrm{Z}}{\mathrm{p}}$ greater than 30 the loss of energy in a collision is comparatively large, so that the velocity of agitation is less than seven times $W$, and in these cases the formula for $\mathrm{W}$ in terms of $l$ and $u$ is not so accurate as in the cases where $\frac{\mathrm{Z}}{p}$ is less than 30 and $u$ comparatively large.

Table II. shows for the higber values of $\frac{\mathrm{Z}}{p}$ that the mean free path increases' with decrease of $u$, but for the lower values it decreases with decrease of velocity of agitation. In the other gases the mean free path increases for the smaller values of the velocity of agitation.

The values of $\lambda$ show that with this gas there is a remarkable increase in the loss of energy of an electron in a collision for comparatively small increases in the velocity of agitation from the values $13 \times 10^{7}$ centimetres to $15 \times 10^{7}$ centimetres per second.

Electrical Laboratory, Oxford, July 1922.

LXXXIX. A Wide Angle Lens for Cloud Recording. By W. N. Bond, M.Sc.(Lond.), A.R.C.S., A.Inst.P., Lecturer in Physics, University College, Reading*.

[Plate VII.]

7 HIS paper consists of a short description of a lens that 1 might be used for obtaining a photographic record of the clouds visible at a meteorological station at definite times, or for similar purposes, such as recording lightning flasbes.

The special feature of the lens is that its field of view embraces a complete hemisphere; so that if the lens be arranged to face vertically upwards, all the clouds visible at the station at any one time can be recorded photographically on a single flat plate or film. The resultant photograph (see Pl. VII.) is circular, any clouds at the zenith being reproduced in the centre of the circle, and any near the horizon appearing near the edge of the circle. Such apparatus might, of course, be used at two stations simultaneously to obtain the altitudes of the clouds.

* Communieated by the Author. 